\title{
Decisão como mediação e representação em Carl Schmitt
}

\author{
Decision as mediation and representation in Carl Schmitt
}

\section{Pedro Hermínio Villas Bôas Castelo Branco ${ }^{[a] b]^{*}}$}

[a] Universidade do Estado do Rio de Janeiro, RJ, Brasil

[b] Universidade Veiga de Almeida, Rio de Janeiro, RJ, Brasil

\section{Resumo}

Este artigo discute como os conceitos de mediação e representação se articulam na reflexão de Carl Schmitt em alguns de seus primeiros escritos e preparam o terreno para a formulação da ideia de representação política em um de seus trabalhos mais conhecidos: Teoria da Constituição. O procedimento mediante o qual se traduz uma realidade amorfa ou um coletivo em forma de representação política se atém à noção de presentificar algo ausente ou tornar visível algo invisível. Toda ideia entra no mundo empírico como hóspede forasteiro e para ganhar existência ou visibilidade necessita de uma decisão soberana pela sua representação. A finalidade deste estudo é explicar o modo pelo qual ocorre este procedimento.

Palavras-chave: Representação. Mediação. Decisão. Secularização. Estado.

* PHVBCB: Doutor, e-mail: pvillasboascb@gmail.com 


\section{Abstract}

This article discusses how the concepts of mediation and representation are articulated in the reflection of Carl Schmitt in some of his early writings and prepare the ground for the formulation of the idea of political representation in one of his best known works: Constitution Theory. The procedure by which an amorphous reality or a collective is translated in the form of political representation is attached to the notion of making something absent presente or making something invisible visible. Every idea enters the empirical world as an outsider and to gain existence or visibility requires a sovereign decision for its representation. The purpose of this study is to explain how this procedure occurs.

Keywords: Representation. Mediation. Decision. Secularization. State.

\section{Introdução}

Representação é um meio imprescindível de dar forma à realidade concreta, consiste em um procedimento de configuração do sujeito coletivo. A representação é uma ideia, uma forma, um modo pelo qual se torna visível o invisível se torna presente ou o ausente. Representar é tornar manifesto por intermédio de um outro presente uma realidade invisível e imperceptível. Este artigo sustenta que o núcleo central da noção de representação política de Carl Schmitt, apresentado na Verfassungslehre (Teoria da Constituição) já havia sido formulado em alguns de seus primeiros escritos. Nos trabalhos Der Wert des Staates und die Bedeutung des Einzelnen (O valor do Estado e o significado do indivíduo) e Die Sichtbarkeit der Kirche, respectivamente publicados em 1914 e 1917. Aludir ao conceito de representação em Schmitt impõe a discussão das relações transcendência e imanência, da secularização e da realização do direito, do modo como se articulam as noções de mediação, decisão, instância, forma. $\mathrm{O}$ argumento principal deste artigo afirma que noção de representação depende de uma ideia se concretizar em meio uma realidade multifacetária. A realização desta ideia 
depende uma da decisão de uma instância concreta de introduzi-la na realidade empírica. Tal decisão, em virtude da perda que sofre toda ideia no ato de sua realização, é uma mediação que em seu estágio final se converte em representação. Sustento que à representação subjaz a perda, a ausência, o invisível, o fato de a decisão soberana somente ser capaz de realizar parcialmente a ideia, o que faz com que represente a parte ausente ou invisível.

Nos primeiros escritos de Carl Schmitt, a decisão política do Estado pela realização do direito consiste numa mediação que se traduz em dois aspectos: o primeiro consiste na decisão de uma instância soberana pela realização de um ideal no mundo real. Contudo, como a decisão jamais transpõe o conteúdo ideal para a realidade em sua plenitude ocorre uma ruptura, uma cisão da ideia ou do ideal normativo. Com isso, chega-se ao segundo aspecto em que o ideal é cindido pela própria estrutura da decisão que o divide em norma do direito e norma de realização do direito. Eis o que permite ao Estado se apresentar como uma forma política de representação do direito, pois surge como um poder político decisório alicerçado no firme e constante empenho de realização do direito. A representação reside num esforço permanente de atualização da ideia de direito que passa pelo crivo ou subjetividade para uma objetividade e configura uma realidade supra-individual. Tal ideia surge no trabalho sobre o valor do Estado como uma secularização em que a instância estatal é única instituição em condições de pôr uma ideia no mundo por meio de uma decisão e tornar visível a ideia perdida por meio de sua representação. Aqui fica claro que um procedimento ficcional tem ressonâncias concretas ao formar a realidade informe por meio da representação da perda, fenômeno típico da experiência moderna que padece de uma transcendência capaz formar uma realidade ontológica. $\mathrm{O}$ trabalho divide-se em duas partes: a primeira trata da mediação e representação como momentos integrantes do conceito de representação e a segunda da relação entre Estado e Igreja, assim como do procedimento de tornar visível o invisível, atividade essencial ao conceito de representação política em Carl Schmitt. 


\section{Decisão como mediação e representação: secularização como realização do direito}

A fim de compreender a mediação levada a cabo pelo Estado, é necessário examinar seu funcionamento interno e suas consequências. A mediação realizada pela decisão estatal estabelece uma ligação entre as duas extremidades do abismo, provocando uma divisão em cada uma dessas margens. De um lado, encontra-se a norma jurídica - dimensão ideal - que, ao ser transposta pela conexão empreendida pelo Estado é penetrada pelo momento empírico, sofrendo uma ruptura em duas partes: direito abstrato e direito estatal. De outro, o Estado entra como mediador do direito no mundo empírico - dimensão real - , tendo que se adaptar ao seu mecanismo de meios e fins. Schmitt explica o problema da seguinte maneira:

pelo fato, porém, de o Estado estabelecer o vínculo entre o direito e o mundo empírico flui um momento do empírico na norma jurídica proclamada pelo Estado que foi atravessada pelo Estado como medium, sofrendo, assim, uma modificação. A plenitude do âmbito do direito empírico decompõe-se desta maneira em dois complexos. O Estado, mediador do direito, entra agindo no mundo e lá tem que adaptar-se segundo seu mecanismo de meio e fim. No mesmo instante em que utiliza o mundo empírico para fazer algo dele, este reage sobre ele com a força, assim como o material de um artista, e determinadas qualidades do criado sobre o senhor. O mundo coloca o Estado na conexão de sua relação e faz com que ele, de modo a atuar sobre o mundo, deva manifestar uma vontade exclusivamente empírica (SCHMITT, 2004, p. 75).

O ingresso do Estado no mundo empírico eleva a tensão entre a ação que busca lhe impor a fim de transformá-lo e a reação do mundo empírico sobre o Estado. O resultado dessa mediação - papel desempenhado pela decisão - operada pelo Estado é a divisão da realidade empírica decorrente da tensão da ação estatal que busca moldar a realidade. Esta, por sua vez, reage à tentativa do Estado opondo-lhe seu modo de funcionamento. De outro lado, no âmbito ideal, o do direito, também ocorre uma divisão. A partir daí, como preconiza Schmitt, surge um "dualismo endógeno" ao direito já acima mencionado: 
o dualismo entre direito abstrato e o direito estatal (SCHMITT, 2004, p. 79). Tal dualismo definiria a estrutura de todo preceito jurídico empírico particular. A decisão do Estado no âmbito ideal ou da ideia do direito provoca uma cisão pela qual o direito é decomposto: de um lado, em direito abstrato definido como originário e dominante na sua relação com o Estado, sendo ele, ao mesmo tempo, um reflexo da manifestação concreta da vontade estatal na realidade empírica. De outro lado, em direito estatal como um direito mediador dirigido a um fim. Este direito não se encontra no que respeita ao direito originário, numa relação de meio e fim. Torna-se fundamental salientar que o fato de tal direito estatal estar voltado para um fim o leva a reconhecer o mundo empírico como espaço de ação: o mundo real consiste no campo efetivo da ação política soberana investida da tarefa de realização do ideal:

de um lado está, portanto, o direito, que lá estava antes do Estado, sendo como ideia independente dele e pode ser designado, na sua relação com o Estado, como direito abstrato, dominante, originário, e na sua relação com as manifestações de vontade concreta que são seu reflexo no mundo empírico; do outro lado, o direito estatal, como direito mediador, servidor, determinado para fins, que não se encontra com o direito originário numa relação de meio e fim, cuja finalidade (Zweckhaftigkeit) baseia-se, ao contrário, no seu reconhecimento do mundo empírico como o do campo de ação (SCHMITT, 2004, p. 76-77).

O eixo central da filosofia política de Schmitt consiste em mostrar que não basta a reivindicação de uma ideia ou a pretensão de um poder se legitimar com base numa ideia ou direito originário. É necessário, primeiro, reconhecer "o mundo empírico como campo de ação". Em seguida, urge a conscientização de que a realização de uma ideia no mundo empírico, a luta pela sua exteriorização e representação consiste num procedimento difícil, marcado por sacrifícios e rupturas inescapáveis à dinâmica da objetivação. Outro ponto é que tal atividade consiste numa ação eminentemente política em virtude de não se buscar sujeitar o exterior à ideia do mundo plural do interior de seres privados, mas um esforço para configurar a própria realidade exterior: encontrar para ela uma forma que significa secularizá-la, 
torná-la visível por intermédio da prática política da ação orientada por ideias. A ontologia de um mundo possível, portanto, é apenas um sonho, caso não surja uma decisão suprema pela sua efetiva realização. Desse modo, as normas jurídicas abstratas pelas quais o Estado se manifesta representam imagens de um mundo, que se pretende possível, direcionadas a moldar à realidade. No entanto, do ponto de vista de Schmitt as ideias devem, em parte - pois a sua transposição ao mundo externo implica sempre perda - , encarnar ou virar realidade, o que não acontece sem uma atividade política mediada pela decisão soberana ou como diz o jurista "um ato de soberana decisão" (Akt souveräner Entscheidung) (SCHMITT, 2004, p. 79).

Umas das tensões do pensamento jurídico e político de Schmitt consiste em assumir o desafio de levar às últimas consequências a relação entre direito e poder. Subjacente a esse empreendimento encontra-se a tarefa da filosofia política: evitar que o poder não seja apenas um poder arbitrário e o direito apenas um normativismo abstrato, uma forma vazia e impotente. Assim, desta perspectiva, verifica-se, por um lado, a insistência em mostrar que o governo das ideias necessita de uma decisão política soberana. Na normalidade, porém, ou na rotina, isto não é de modo algum evidente, devido à propensão a considerar o governo das ideias ou leis como algo natural, imanente à natureza fática dos eventos históricos. Contra tal postura, Schmitt opõe um pensamento político capaz de assimilar crises. Não se trata de um estilo dramático, mas de um pensamento que não esmorece diante do vaivém da vida humana, marcada pela inescapável real possibilidade da ordem sair dos eixos.

Por outro lado, a filosofia do Estado de Schmitt acentua a imprescindibilidade da ação política, pois ideias não se aplicam a si mesmas, não caem do céu, não são logicamente deduzidas. O problema é que a realização da ideia do direito envolve sempre uma decisão cuja estrutura própria divide a norma entre o direito abstrato originário e sua realização. A distinção entre direito abstrato e direito estatal é retomada por Schmitt no trabalho Die Diktatur (1921), mediante a discussão sobre a norma do direito (Rechtsnorm) e norma de realização do direito (Rechtsverwirklichungsnorm). Sua importância se relaciona à 
irredutibilidade de parte da norma à realidade objetiva concreta. Isso significa que na estrutura normativa do direito estatal há algo, um elemento do direito não-estatal e originário. Há, na estrutura de norma jurídica, ou em todo preceito jurídico, um aspecto originário chamado de "direito natural sem naturalismo". Schmitt elucida a expressão como

aquilo que determina o preceito jurídico e o que o distingue apoia-se no elemento originário, não-estatal do direito, cuja definição mais aproximada não é a tarefa deste tratado e do qual somente deve ser dito (para ser conciso diante do perigo do paradoxo) que ele deve aparecer como um direito natural sem naturalismo (Naturrecht ohne Naturalismus) (SCHMITT, 2004, p. 77).

A expressão "direito natural sem naturalismo" suscitou mal-entendidos e ambiguidades. Alguns viram em Schmitt um jusnaturalista, outros um positivista. O próprio autor se queixa de tais equívocos no prefácio de Die Diktatur (SCHMITT, 1994f, p. XX). A aludida expressão serve como síntese das ideias do autor, pois revela o caráter secularizante de seu propósito. Mas ainda vale perguntar: o que, afinal, significaria a expressão "direito natural sem naturalismo"? Segundo o jurista, "no interior de todo preceito estatal deve-se ocupar de uma separação da ideia do direito dos momentos que se referem à realização e execução" (SCHMITT, 2004, p. 77). Entre norma do direito e sua realização haveria sempre uma distinção, pois na realização ou execução da norma há algo do direito não-estatal, que a despeito de emitir seus reflexos, não se realiza, não se reduz à faticidade empírica. A irredutibilidade do ideal no real é levada a sério por Schmitt, uma vez que envolve a estrutura da teoria da decisão e o problema da secularização. $\mathrm{O}$ direito natural sem naturalismo se apresenta como uma dimensão autônoma de cada preceito jurídico, um aspecto não-estatal do direito que não se realiza, de modo que não se torna um direito positivo concreto.

Parece-me que a chave para decifrar o enigma do "direito natural sem naturalismo" reside no fato de que a decisão pela realização do direito implica sempre numa distinção, numa cisão entre a ideia e a realidade, entre o ideal e sua efetivação, entre o que é transcendente e o que se tornaria imanente ao mundo empírico. A decisão leva ao 
sacrifício da ideia em nome de sua passagem de um subjetivo para um objetivo, portanto para um novo estado. Todavia, há sempre algo que não passa pela mediação feita pelo poder político supremo. Este algo, elemento ou princípio originário irredutível, é a parte não realizável da norma, portanto, ideal. Aqui entra em questão o aspecto da representação, pois da perspectiva de Carl Schmitt a representação exige transcendência, portanto, algo que não se torne imanente ou que não se reduza à mera faticidade empírica ou necessidade de permanente objetividade. A imanência empírica, os fatos, ou mesmo o direito que é positivado, exteriorizado, não tem capacidade de representação, pois se tornou algo concreto e presente. Ao contrário da parte do direito que encarnou ou se tornou realidade concreta, aquela parte do preceito jurídico, elemento não-estatal, pode assumir uma forma visível. Em outras palavras, para Schmitt, as ideias não encarnam plenamente na realidade, não podem se reduzir totalmente a uma objetividade concreta: não pode prevalecer o triunfo da objetividade absoluta como provocada pelo tecnicismo da era mecânica.

Em virtude disso, insisto em reiterar que continuidade, a duração de um poder político, "a eternidade artificial da vida" do Estado, ou de sua alma, como dizia Hobbes ${ }^{1}$, somente pode residir na forma e não na matéria perecível. Somente a ideia, a forma, pode se elevar acima da faticidade da realidade, alcançando continuidade. Tal questão se verifica na centralidade assumida pela decisão no pensamento de Schmitt. Por essa razão a aplicação ou transposição de uma ideia ou norma jurídica a um caso concreto atinge as partes envolvidas no litígio. A parte da norma jurídica que se concretiza é relevante, mas tem efeito limitado

\footnotetext{
1 Um das ideias centrais do Leviatã de Hobbes consiste na investigação da relação entre matéria e forma, capaz de definir a continuidade ou imortalidade do Estado. 0 Leviatã, que compõe o título do livro de Hobbes, é carregado de tamanha força que costuma eclipsar o restante do título que a ele se segue, pois 0 autor o denominara de Leviatã ou matéria, forma e poder de um Estado eclesiástico e civil. A constituição e manutenção de um corpo político cuja existência não estivesse apenas vinculada à precariedade da matéria, mas unidade entre forma e matéria, entre o espiritual (invisível) e o temporal (visível). A partir da análise de diversas formas de governo por instituição, Hobbes conclui que "a matéria de todas estas formas de governo é mortal, de modo que não apenas monarcas morrem, mas também assembleias inteiras; é necessário para a conservação da paz entre os homens que, do mesmo modo que foram tomadas medidas para criação do homem artificial, sejam tomadas medidas para uma eternidade artificial da vida" (HOBBES, 1983, p.119). A eternidade artificial da vida somente existe na ideia.
}

Rev. Filos., Aurora, Curitiba, v. 29, n. 47, p. 481-502, maio/ago. 2017 
às referidas partes, sendo incapaz de se erguer frente a elas e alcançar uma continuidade, pois se tornou uma realidade fática. É certo que todo direito, para Schmitt, é um direito situacional. Não se deve, porém, perder de vista que parte do preceito irredutível à realidade fática é transcendente, podendo tornar-se visível pela representação de um poder político que decide com base em algo distinto da força física. Decidir significa sempre um desligamento do conteúdo normativo da ideia a ser realizada, de modo que apesar de essa ideia orientar a deliberação, não se realiza plenamente, mas produz efeitos na realidade. Desse modo, na estrutura de toda decisão há uma exceção. Schmitt já havia anunciado em Gesetz und Urteil que "toda atividade psíquica se alicerça num processo evidentemente voluntarístico; toda decisão num avaliar e querer" (SCHMITT, 1912, p. 99 e 100).

A decisão não apenas se torna autônoma frente à parte da ideia que se concretizou na realidade, mas também é autônoma em relação à ideia originária que não se realiza. Por isso, creio ser fundamental entender que o Estado deve ser a parcial encarnação - e nunca plena encarnação - do ideal do direito por meio do exercício continuo da atividade decisória. Isto significa que o esforço pela realização da ideia consiste numa tensão constante entre a ideia invisível e a realidade concreta. Assim, é possível concluir que o poder político soberano dedicado à tarefa de positivar normas jurídicas no mundo empírico se deve à própria estrutura da decisão soberana - a cisão entre ideal e real - a possibilidade de configurar a realidade do mundo. A possibilidade de transformação ${ }^{2}$ da realidade do mundo empírico pela decisão deve-se à estrutura do direito, mas também à da própria realidade que contém um dualismo entre o abstrato e o concreto. Schmitt, em Gesetz und Urteil (Lei e Julgamento), publicado pela primeira vez em 1912, ao se confrontar com a Filosofia do direito de Hegel, concluía, ao contrário do

2 "Schmitt explica que"a ideia do direito que deve servir como uma diretriz para a transformação (Umgestaltung) da realidade tem que ser positiva, isto é, seu conteúdo é posto (gesetzt) mediante um ato de decisão soberana, convertendo-se num preceito declarado numa moldura concreta" (SCHMITT, 2004, p.79). 0 fato de que a ideia tem de ser positiva, ou seja, realizada, para a transformação da realidade, implica "moldura concreta", isto é, sua forma concreta. A forma concreta somente seria possível em virtude da estrutura dualista da norma". Em outras palavras, o Estado é capaz de proteger, por meio da forma, a norma jurídica frente às forças da realidade. 
filósofo, que a ruptura no direito não era periférica ao direito, mas central. A contraposição entre teoria e práxis mostrava a ruptura existente no direito. Tal ruptura, embora apontada no direito, como disse, revela traço imanente à própria realidade do ser. De acordo com Schmitt

entre todo concreto (Konkretum) e todo abstrato (Abstractum) reside um abismo insuperável que não pode ser fechado por meio de nenhuma passagem gradual. Por isso, é necessário que em cada lei positiva este momento do puro ser estabelecido (Festgestelltseins) venha a ser válido, segundo o qual, é mais importante, sob algumas circunstâncias, quese transforme de qualquer maneira alguma coisa em determinação positiva e não em algum conteúdo concreto. Esta indiferença com relação ao conteúdo - e essa relação é fornecida com a explanação de meu tratado "GesetzundUrteil" - resulta do empenho de realização (Verwirklichungsbestreben) por parte do Estado (SCHMITT, 2004, p. 80, grifo meu).

Não há como superar o abismo entre "todo concreto e abstrato". No entanto, as margens do abismo podem ser ligadas por uma espécie de mediação cuja característica é "um ato de decisão soberana". Ainda assim há, neste caso, uma questão existencial que impede uma razão capaz de constituir a imutabilidade, a eternidade, fundada numa natureza humana. A necessidade de transformar a realidade mediante a ideia e representá-la por meio de um ato soberano já revela a noção do limite da atuação das normas e da exceção presente em toda realização do direito. Por isso, Schmitt afirma que:

A renúncia à correção (Richtigkeit) imutável e recepção do momento de indiferença quanto ao conteúdo são consequências [...] do direito, o sacrifício que teve de ser feito por ter se pactuado com os poderes do mundo fenomênico (SCHMITT, 2004, p. 81).

Ainda a respeito da expressão "direito natural sem naturalismo" verifica-se uma provocação nítida ao positivismo jurídico pelo qual o direito é reduzido à sua manifestação fática. A negação do naturalismo 
do direito natural visa a afirmar a inexistência da natureza humana imutável e de uma realidade objetiva unívoca.

A passagem na qual Schmitt emprega pela primeira vez o termo secularização desempenha o papel de uma síntese do pensamento do autor em diversos trabalhos:

Deve-se, ainda, chamar a atenção para um fenômeno cuja discussão constitui, adequadamente, a conclusão sobre Estado e direito: tão logo se manifeste em alguma parte o esforço de uma realização de ideias, de um tornar visível (Sichtbarmachung) e de uma secularização, surge imediatamente - ao lado de uma decisão concreta que tem de ser, sobretudo, determinada mesmo que seja à custa do pensamento - o empenho por uma instância determinada da mesma forma e infalível, que conceda esta formulação (SCHMITT, 2004, p. 81).

Além de a passagem acima mencionada revelar, pela primeira vez - no conjunto extenso dos trabalhos de Schmitt - o primeiro emprego da palavra secularização, ela também reúne os elementos centrais que definem seu sentido. De um lado, a expressão precedente ao termo secularização revela "um esforço de uma realização de ideias", um empenho em "tornar visível" a ideia que na filosofia do Estado de Schmitt corresponde à ideia do direito. Do outro lado, o autor menciona o surgimento do momento da "decisão concreta" e o esforço por uma "instância" cujo caráter seja infalível. O empenho pela realização de ideias, a visibilidade, a decisão e a instância compõem o conteúdo semântico da secularização e definem o conceito do Estado a partir de sua relação com o direito. É notável que a ênfase no esforço pela realização, pelo tornar visível a ideia, não se efetiva sem o sujeito e uma instância absoluta em razão de sua primazia em relação aos outros poderes da realidade empírica. $\mathrm{O}$ esforço para conferir visibilidade à ideia decorre da ruptura existente na realidade, do vácuo, da própria ausência da ideia, cuja realização depende de sua passagem para a realidade pela via da decisão de uma instância suprema. Tal decisão não é a de um sujeito empírico particular qualquer imediatamente entregue à ideia, à sua autodeterminação, mas um sujeito empírico capaz de se vincular à ideia exterior, ao relativismo empírico da realidade. Uma 
instância capaz de uma decisão voltada para a realização de um ideal supra-individual, voltado para a transformação da realidade. A secularização assume o sentido de uma ideia que encarna na realidade a fim de transformá-la. Essa ideia do direito representa a formulação de uma imagem com a qual se pretende configurar a realidade política e social a partir da transposição ou mediação que o poder fático realiza para o âmbito da realidade concreta.

A decisão política em condições de realizar um ideal só pode partir de uma instância superior que se encontra numa posição, estruturalmente, análoga à de Jesus Cristo pelo fato de proceder de cima para baixo. A mediação da ideia depende de um sujeito cuja estatura e força permita viabilizar sua passagem à realidade. Essa passagem significa um processo de objetivação pela via da subjetivação mediadora do sujeito da instância superior. A decisão e a instância devem ser infalíveis no sentido de não poderem ser reduzidas a uma vontade meramente arbitrária, mas de ligar-se a um princípio, a uma ideia cuja realização depende de um medium homogêneo. Todavia, cabe levar em conta que pôr uma ideia no mundo real a fim de lhe dar uma direção, uma ordem jurídica, implica um sacrifício, pois a transposição da ideia à realidade sempre ocorre à custa do pensamento. A ideia invisível tem que passar pela mediação feita pelo sujeito soberano do direito sob o abismo da contingência. Esta mediação ou secularização implica uma decisão política que sacrifica a ideia na tensão para torná-la visível. $\mathrm{O}$ pôr a ideia no mundo depende da subjetivação do ideal pelo sujeito do direito. A subjetivação, ou processo de mediação, implica tornar o invisível em visível à custa do pensamento, pois a ideia não se realiza plenamente, não encarna plenamente na realidade.

\section{Analogia entre Estado e Igreja: o invisível no visível}

No trabalho Sichtbarkeit der Kirche (Visibilidade da Igreja), publicado em 1917, verifica-se que o procedimento de objetivação para tornar o invisível visível depende da transcendência do poder. Alega Schmitt que: 
um procedimento para fazer valer o invisível no visível deve estar enraizado no invisível e aparecer no visível. O mediador descende, pois a mediação somente pode proceder de cima para baixo, não de baixo para cima. A salvação encontra-se no fato de que Deus torna-se homem (não que o homem torna-se Deus) (SCHMITT, 2005, p. 448).

Aqui se percebe como a estrutura da secularização apresentada em Der Wert des Staates encontra sua estrutura análoga no papel desempenhado por um Deus que se faz homem e de modo algum o homem que se faz Deus. Vale elucidar que a secularização não surge aqui no sentido negativo da ocupação da posição de Deus pelo indivíduo considerado como instância absoluta, como Schmitt mostra no Romantismo Político, mas por uma instância terrena de decisão última. A passagem acima revela que a mediação consiste numa decisão cuja estrutura transcendental procede do invisível ao visível, "de cima para baixo", da subjetividade de uma autoridade última à objetivação de um ideal numa realidade informe e contingente. Essa passagem ou tradução de uma perspectiva ideal invisível à dimensão real concreta jamais se faz sem dificuldades, de modo que "a ideia adquire na palavra sua visibilidade como um bafejo de ar que somente se torna um som pelo fato de ser impelido através de tubo estreito" (SCHMITT, 2005, p. 451).

Somente a transcendência da ideia mediada pela decisão estatal poderia conferir unidade à indeterminação da realidade concreta. A unidade conferida pelo Estado à realidade informe é extraída da unidade da ideia do direito. A posição estrutural ocupada pelo Estado de Schmitt em Der Wert desStaates é semelhante à unidade promovida pela mediação de Deus em Sichtbarkeit der Kirche: "a unidade de Deus assume a forma de uma sucessão jurídica na historicidade de uma mediação através da mortalidade dos homens, tornando somente assim visível a temporalidade (Zeitlichkeit)" (SCHMITT, 2005, p. 451). A visibilidade que Deus atinge através da Igreja não coincide com a Igreja concreta. Isso significa que a Igreja não coincide com seu representante concreto. Esta é uma questão relevante para a teoria do Estado de Schmitt, pois ilustra uma distinção entre uma visibilidade verdadeira e a concretude fática. 
A meu ver, a reflexão político-jurídica de Carl Schmitt está em plena consonância com a ambição hobbesiana de encontrar um meio de eternizar artificialmente a vida do Estado $^{3}$ por meio de analogias com o sentido jurídico da estrutura hierárquica forjado pela doutrina católica romana. Em Der Wert des Staates, Schmitt mostra como, por meio da compreensão de um determinado significado do conceito de ficção, tanto a jurisprudência quanto a teologia revelam a "soberania com que se comportam diante da mera realidade fática" (SCHMITT, 2004, p. 101). O conceito de ficção surge no sentido de Vahinger como "consciência de uma suposição falsa". Para Schmitt, "o vasto campo da ficção", pouco explorado pelo direito, propiciaria o exame do real sem tomá-lo como algo imediato fundado em si mesmo, o que possibilita considerá-lo de um ponto de vista ideal: a ficção pode "conceder uma auscultação do 'real' (Tatsache) e suscitar sua ponderação, sem que o 'real' assume uma significação autônoma". A realidade não é estática, unívoca ou pura regularidade mecânica, não se reduzindo à manifestação de fatos externos. A abertura da realidade, a demolição de sua fachada meramente fática, não pode se furtar à percepção de um procedimento interno do desígnio de um indivíduo dirigido ao plano externo de sua ação.

Schmitt já havia se ocupado deste sentido em sua tese de doutorado ÜberSchuldundSchuldarten (Sobre a culpa e os tipos de culpa), publicada em 1910, da trajetória interna pela qual um propósito de um sujeito particular se converte numa ação externa. Embora Schmitt não mencionasse o termo secularização, já o investigava na medida em que, através da análise do dolo e das formas de culpa, buscava compreender a objetivação de uma finalidade. Analisando o procedimento pelo qual uma ideia intencionada ou dolo - invisível devido à sua subjetividade - se manifesta na realidade, buscava romper com a visão mecânica do positivismo. Ao examinar as formas de culpa, buscava compreender que ações seriam imputáveis pelo Estado, isto é, quais ações seriam objeto da atribuição de um sentido juridicamente relevante. Concluía que o "que não chega de modo algum a se manifestar externamente,

3 Ver, nesse sentido, Thomas Hobbes (HOBBES, 1985, p. 247).

Rev. Filos., Aurora, Curitiba, v. 29, n. 47, p. 481-502, maio/ago. 2017 
permanece impunível, mas o que vem a se manifestar externamente não é apreciado segundo a medida de sua manifestação, mas de acordo com o movimento espiritual interno" (SCHMITT, 1910, p. 30). A objetivação ou manifestação externa da culpa não aparecia como efeito de uma causa, mas como realização de uma vontade de um homem orientada para um fim determinado: "culpa é o concreto estabelecimento de um fim, não correspondente ao direito" (SCHMITT, 1910, p. 92).

Em Der WertdesStaates, a ficção torna-se um recurso importante para conhecer ou auscultar a realidade do ponto de vista da trajetória de um processo interno do sujeito de um ideal. Não se deve imaginar que interesse ao jurista investigar toda sorte de desenrolar interno no mundo mental. Se isso não fosse verdade, não estabeleceria uma distinção entre crime de castigo. Conforme seu ponto de vista, crime não é forma secularizada do pecado, pois não há transferência da moralidade teológica para o âmbito temporal. O conceito de secularização schmittiano não é concebido como analogia ens, mas como realização de uma ideia no mundo, pela força política máxima da realidade empírica. Desse modo, é impossível definir o que é crime fora da existência do corpo político do Estado, instância última de decisão sobre qual finalidade levada a cabo por uma ação é juridicamente relevante. A "culpa"

é algo intrassubjetivo. Para o direito vigente somente é levada em consideração a culpa que surge de forma perceptível no mundo fenomêni$\mathrm{co}$, o que permanece oculto na alma não pode ser tratado pelo direito cogitationispoenamnemopatitur (ninguém deve ser punido pelos seus pensamentos) (SCHMITT, 1910, p. 28).

A meu ver, tal passagem é indispensável para alguns críticos de Schmitt que se esforçam em esvaziar o caráter jurídico e político de seu pensamento a partir do argumento de que suas ideias partem de um fundamento moral ou ético-religioso. O conhecimento de seus primeiros trabalhos de juventude permite desfazer equívocos de intérpretes que tomam como ponto de partida de suas interpretações a origem católica ${ }^{4}$

4 Hasso Hofmann adverte, com razão, que "é correto que Schmitt é desde o começo católico, tanto no trabalho aqui tratado sobre 0 valor do Estado, como também posteriormente, quando chamou a atenção para a importância do catolicismo para 
de Schmitt. Há, inequivocamente, uma relação de seu pensamento com o catolicismo romano, mas esta é apenas de caráter metódico.

Em Der Wert des Staates a realidade é examinada como manifestação externa, mas que não deixa de ser confrontada com o desenrolar de um procedimento interno fundado numa pretensão compreendida como realização de uma continuidade conforme uma vontade. Justamente por isso, Schmitt alude ao antinaturalismo (Antinaturalismus) como vontade tornada válida defronte de acontecimentos particulares e fatos típicos "capazes de uma vitória sobre os fatos contingentes". O que está em jogo é encontrar na jurisprudência uma estrutura análoga à da teologia a fim dotar de continuidade no âmbito da realidade. Ao perseguir a longevidade do Estado, o jurista investiga institutos jurídicos ligados à ideia de imortalidade pelo qual uma disposição de vontade produz efeitos na realidade:

o caso mais claro é o modo de imortalidade que o direito alcançou por meio do instituto jurídico da herança e tornou notório nesse fenômeno mais elementar da vida do direito a superioridade sobre as categorias biológicas e da história natural (SCHMITT, 2004, p. 103).

O testamento seria um exemplo notável da continuidade de um sentido pelo qual o testador encontraria sua eternidade artificial através de uma construção do direito: pessoa jurídica (SCHMITT, 2004, p. 104). O exemplo mais convincente, porém, seria oferecido pela “doutrina católica romana com a sua constituição do charismaveritatis através da simples concessão do ofício de modo que o ofício não se alicerça mais no charisma, mas a concessão é constitutiva para o charisma" (SCHMITT, 2004, p. 102). Schmitt apresenta uma ideia de carisma bastante diferente daquela de Weber, já que o indivíduo que ocupa o ofício seria investido da própria subjetividade jurídica a fim de evitar por meio de tal instituição o exercício arbitrário do poder por parte do indivíduo concreto. Segundo Schmitt,

a metodologia da ciência do direito, mas somente para a metodologia" (HOFMANN, 2002, p. 50). 
esta ideia, que, aliás, pertence ao jus divinum da Igreja é, num sentido eminente, jurídico (e anti-individualista): diante do ofício, que é administrado pela pessoa concreta, não podendo fazer valer suas características pessoais, concretas, e a expressão segundo a qual a quem Deus dá o ofício, também concede o juízo necessário, não é apenas de interesse sociológico, mas jurídico (SCHMITT, 2004, p. 102).

A ficção permite a construção ideal de uma pessoa jurídica capaz de influenciar a realidade, capaz de moldar o indivíduo concreto num sujeito de direito. Desse modo, “a palavra ficção contém apenas uma referência à realidade externa e não explica a pessoa jurídica como uma mentira ou figura arbitrária enquanto o indivíduo humano particular for o 'verdadeiro' sujeito de direito" (SCHMITT, 2004, p. 103). Schmitt se empenha em encontrar, por meio da construção jurídica, a transformação de uma pessoa concreta num "real portador do direito". A dedicação à ficção, além de buscar a continuidade de uma ideia na realidade, pretende envolver o indivíduo concreto num ideal que se eleve à arbitrariedade dos interesses particulares.

A meu ver, Schmitt concebe a pessoa jurídica no mesmo sentido apresentado por Hobbes no Leviatã. O autor inglês afirma que "pessoa fictícia ou artificial" seria "aquele cujas palavras ou ações são consideradas [...] como representando as palavras ou ações de outro homem, ou de qualquer coisa a que sejam atribuídas, seja como verdade ou por ficção" (HOBBES, 1983, p. 96). Assim se compreende a importância da ficção como artificialidade que veste a pessoa concreta de responsabilidade, da consciência de um sentido transcendente a qualquer relativismo particularista do mundo empírico. De acordo com Schmitt "a pessoa jurídica 'fictícia' é o arquétipo de toda pessoa no direito" (SCHMITT, 2004, p. 104). Com efeito, o autor acentua o caráter antinaturalista, antimaterialista e mecanicista da pessoa fictícia que somente ganha existência mediante uma decisão política. Trata-se de realização que jamais pode abrir mão de um processo interno de um sujeito da realidade concreta.

A conclusão da tríade "direito, Estado e indivíduo" de Schmitt pode ser sintetizada pela secularização cujo sentido reside na decisão 
de uma instância superior em tornar visível uma ideia invisível, a fim conferir unidade à realidade indeterminada. Há um movimento entre a ausência de uma ordem jurídica e sua atualização por meio da realização do direito. A secularização consiste, portanto, num difícil e constante procedimento de transpor uma ideia para a realidade concreta, descrever um processo de realização do ideal de direito que jamais se esgota na realidade concreta. A secularização de um ideal pressupõe uma realidade contingente, sempre dependente de uma decisão política soberana. Secularização consiste na realização do direito, um processo constante de decisão e representação. Ela é composta pelos seguintes elementos: instância superior-decisão (mediação)-representação (tornar visível um invisível).

O sentido de representação apresentado na Verfassungslehre (Teoria da constituição) (1928) se aproxima do sentido com que Schmitt emprega a secularização em Der Wert des Staates:

representar significa que um ser invisível é tornado visível e presentificado através de ser presente publicamente. A dialética do conceito reside no fato de que o invisível é pressuposto como ausente e, contudo, é, ao mesmo tempo, tornado presente. Algo morto, algo desqualificado ou destituído de valor, algo inferior, não pode ser representado. Falta-lhe uma espécie elevada de ser que seja capaz de sobressair-se até a esfera do ser público, que seja capaz de existência. As palavras grandeza, alteza, majestade, glória, dignidade e honra buscam encontrar esta singularidade do ser elevado e capaz de representação. O que somente serve às coisas privadas e aos interesses privados pode, é certo, ser representado; pode encontrar seus agentes, advogados e exponentes, mas nunca será representado num sentido específico. Ou é realmente presente ou é percebido por um comissário dependente, encarregado de negócios ou um mandatário. Em contrapartida, na representação, uma espécie mais elevada do ser se manifesta concretamente (SCHMITT, 2003, p. 209).

De forma semelhante à secularização em Der Wert des Staates, a representação na Verfassungslehre surge como tornar visível uma ideia invisível. O invisível é suposto como ausente, pois a unidade política não existe na realidade concreta informe e contingente. Enquanto em 
Der Wert des Staates Schmitt insiste em que a realidade concreta é incapaz de forma, de representação, na Verfassungslehre observa que o povo não é representado na sua "existência natural" (SCHMITT, 2003, p. 212). Tampouco os interesses particulares, os seres privados ou o ser empírico particular podem ser representados num sentido especificamente político. Na representação, apresentada na Verfassungslehre, "um modo elevado do ser atinge uma manifestação concreta" (SCHMITT, 2003, p. 210). Em Der Wert des Staates só uma instância suprema da realidade do ser pode decidir pela mediação entre a ideia do direito e a realidade. É interessante perceber que na Verfassungslehre também aparece a necessidade de "um ser elevado e capaz de representação". A preocupação recorrente de Schmitt em alertar que somente um ser elevado existente na realidade concreta é capaz de representar, se justifica em virtude do tecnicismo cuja expansão acomete o próprio Estado. O tecnicismo dilui qualquer hierarquia, autoridade, ideia transcendente na imanência, no niilismo.

A imagem hobbesiana do Estado como máquina ou machina machinarum havia se tornado uma realidade no início do século XX e sua progressiva mecanização o convertia num instrumento ou aparelho técnico desvencilhado de um fim. Destituída de um princípio, fim, e portanto, limites, a máquina estatal converte-se num aparelho ou instrumento a serviço de interesses particulares. Por esse motivo, Schmitt declara que "diante de autômatos e máquinas não se pode representar da mesma forma como eles não podem representar ou ser representados quando o Estado se tornar um Leviatã, e terá então desaparecido do mundo representativo" (SCHMITT, 1984, p. 36). A perda da ideia política transcendente, pela qual o Estado recebe seu sentido, o transforma num meio técnico e desvencilhado de uma finalidade exterior à esfera particular. Frente à tecnicização, à perda de transcendência, à perda de valores, Schmitt utiliza o conceito de secularização em seu trabalho Theodor Däubler's Nordlicht (1916) num sentido bem diferente de Der Wert des Staates:

as coisas mais importantes e últimas já foram secularizadas. O direito foi transformado em força, fidelidade em calculabilidade, verdade em 
correção geralmente reconhecida, beleza em bom gosto, o cristianismo numa organização pacifista (SCHMITT, 1991, p. 61).

A secularização surge de forma pejorativa como perda das referências últimas, do deslocamento de representações de transcendência para representações de imanência. A descrição pela qual o direito se torna mera força revela que a secularização permite conhecer a crise pela qual a força, destituída de sentido, se torna realidade niilista. Creio que nesse caso a secularização aparece num sentido extremamente importante, porém menos original do que o sentido analisado em Der Wert des Staates: Rechtsverwirklichung.

\section{Considerações finais}

A ausência, característica estrutural de uma realidade considerada dualista por Schmitt, expõe a carência de um princípio de representação, revelando a necessidade ${ }^{5}$ de uma ideia do direito. A realidade invisível e ausente traduz a incapacidade deste mundo explicar-se por si mesmo, como cápsula, autossuficiente e fechada em si mesma. O rompimento da cápsula surge no momento da crise ou de uma situação extrema, excepcional, na qual a regularidade imanente ao mundo encapsulado sofre uma ausência pela qual se torna evidente a até então encoberta divisão entre ideia e realidade. A realidade desperta de sua posição encapsulada ou de seu autismo e torna-se patente a ausência e, com isso, a ideia, precisamente de uma propensão para a realização da ideia. Na ausência, no hiato, no abismo, torna-se patente à realidade concreta, contingente, não só a insuficiência de sua imanência, mas a ideia e sua necessidade de encarnação - que nunca é plena - na realidade.

\footnotetext{
"Necessidade" não deve ser tomada aqui como um determinismo, mas como uma propensão à realização que irrompe nas situações-limite, ou, como depois dirá Schmitt, nas situações extremas de falência normativa traduzidas pela ideia de exceção. Se, porventura, este aspecto é ignorado, priva-se o conceito de secularização de seu sentido de realização do direito, que depende de uma ação política soberana.
} 
O surgimento da ideia a partir da ausência e invisibilidade abre a realidade à secularização compreendida como o empenho da ação política soberana pela realização do ideal. Tal ação reside na mediação e ordenação da estrutura dualista da realidade, conferindo-lhe uma unidade, o que não significa a superação da ausência, mas uma mediação capaz de ordenar as contradições e oposições da realidade concreta. Assim, Schmitt, no trabalho Römischer Katholizismusund Politische Form (Catolicismo romano e forma política), desenvolve a ideia de complexio oppositorum: um princípio agregador capaz de abarcar as oposições extremas. A capacidade de abarcar um complexo de oposições extremas se fundaria numa vontade de decisão cuja realização impõe à realidade, informe e irredutível às mediações dialéticas hegelianas, uma forma agregadora. A formulação desse conceito, pensado a partir da analogia entre a decisão política e o dogma da infalibilidade da decisão papal elaborada pelo direito canônico, encontra suas raízes em Der Wert des Staates.

O pensamento político de Schmitt nos ensina que somente na crise profunda, no caso-limite, nas situações extremas funda-se uma ordem política capaz de criar uma "situação normal". Somente depois é possível realizar o direito. A secularização, nesta interpretação, pressupõe a neutralização dos conflitos para, em seguida, poder pôr o direito num mundo cheio de tensões. Não é possível realizar o direito frente a situações extremas de revoluções e guerras civis. Schmitt amplia os sentidos do conceito de secularização para dar contra, creio, das nuanças que se revelam num pensamento conceitual que quer desvendar crises, mas concomitantemente, intenta provocar mudanças na realidade.

\section{Referências}

SCHMITT, C. "Die Sichtbarkeit der Kirche. Eine scholastische Erwägung". In: Ernst HÜSMERT, E.; GIESLER, G. (Org.). Carl Schmitt. Die Militärzeit 1915 bis 1919. Tagebuch Februar bis Dezember 1915. Aufsätze und Materialen. Berlin: Akademie Verlag, 2005. p. 445-452. 
SCHMITT, C. Der Wert des Staates und die Bedeutung des Einzelnen. Berlin: Duncker \& Humblot, 2004.

SCHMITT, C. Verfassungslehre. Berlin: Duncker \& Humblot, 2003.

SCHMITT, C. Theodor Däublers "Nordlicht". Drei Studien über die Elemente, den Geist und die Aktualität des Werkes. Berlin: Duncker \&Humblot, 1991.

SCHMITT, C. Gesetz und Urteil. Eine Untersuchung zum Problem der Rechtspraxis. Berlin: Verlag von Otto Liebmann, 1912.

SCHMITT, C. Über Schuld und Schuldarten. Eine terminologische Untersuchung. Breslau: Schletter'sche Buchhandlung, 1910.

SCHMITT, C. Römischer Katholizismus und politische Form. Berlin: Klett-Cotta, 1984.

Recebido: $14 / 05 / 2017$

Received: 05/14/2017

Aprovado: 10/07/2017

Approved: 07/10/2017 